\title{
Social services, social work, and information management: some European perspectives
}

\author{
by Jan Steyaert and Nick Gould
}

\begin{abstract}
Social services are entering the information society. Over the past decades, information technology applications have slowly permeated service agencies. Although originally the domain of administrative and management staff, now core operational staff are also confronted with making increased use of technology. The way information management in human services is shaped is not only dependent upon technology, but increasingly seems to result from an interaction between social policy developments and information technology opportunities. Similarly, social policy developments are shaped by the existing information management infrastructure. One of the purposes of this paper is to explore-taking social services and social work as the exemplar, and mainly drawing upon experiences from the UK and the Netherlands-the relationship between new technology and the policy environment. We also reflect on whether or not this relationship is more complex than indicated by globalization and related post-fordist theories.
\end{abstract}

\section{Introduction}

Modern industry bas establisbed the world-market, for which the discovery of America paved the way. This market bas given an immense development to commerce, to navigation, to communication by Land. This development bas in its turn reacted on the extension of industry; and in proportion as industry, commerce, navigation railways extended, in the same proportion the bourgeoisie developed, increased its capital, and pusbed into the background every class banded down from the Middle Ages (Marx and Engels 1848).

Although it may be deeply unfashionable these days to quote directly from Marx and Engels, it may be as well to remind ourselves that within political economy there is a longstanding recognition of the complex interaction between the development of technology, pacterns of economic relationships, and social scructure, and that this interaction has an international, globalizing cendency. The emergence in recent social science of debates around the concepts of globalization and post-Fordism are continuations of well-escablished avenues of empirical and theoretical inquiry. Indeed the preoccupations of the globalization debate are strongly prefigured by Marx and Engels: to what extent is the internationalization of the world economy, facilitated in particular by developments in communication technology, creating a new economic imperative, that is the imposition of global marker efficiency upon the domestic supply of goods and services? This technology-based global market principle has impacted on the organizational form of companies to move from Fordist patterns of mass production to post-Fordist flexible network structures.

Now attention is turning to whether the same analysis can be applied to the production of social services. Is the combined logic of new technology and global capitalism, the drive for Hexibility and accumulation of capical, also derermining the policy concext for welfare (Burrows and Loader 1994)? This analysis has two aspects. First, there is a proposition that costs of welfare are a brake upon economic competitiveness and efficiency (Gough 1996), and that there is a need for national governments to control and reduce expendicure on welfare by shifting costs to the individual and provision to the private sector. The second aspect, which follows from the first, is the belief that the operation of welfare services should mirror the mechanisms of the market economy. Thus several authors (e.g. Dominelli and 
Hoogvelt 1996; Ferge 1997; Trevillion 1996) argue that technologization, globalization of the world economy, and the shift to consumption-led post-Fordist forms of organization are producing specific changes in the production of social services. In summary these changes include:

1. the repositioning of professional social work within the control and delivery of services;

2. the espousal of demand-driven (or 'needs-led') service development;

3. the introduction of markets, separating the commissioning and supply of services; and

4. the realignment of the state in relation to the provision and regulation of services.

It is not our intention in this paper to offer a specitic critique of these cheories of technologization and globalization, but to draw attention to the fact that they have important implications for developments in information management in social services. Furthermore, instead of accepring a rechnological dererminism which is pessimistic in its implications and demonizes information and communication rechnology, are there grounds for conceptualizing a more complex, though still critical, understanding of the relationship between technology, information management, and the capacity of social services to respond to need? Our definition of information management is thus nor limited to the narrow technical questions of information technology implementation, but covers the broad combination of technology and methodology (compurer-based or otherwise) to support the collection, storage, processing, retrieval, distriburion, and management of information (Gould 1996). For most agencies this will encompass management information systems, client information systems, resource directories, and financial and planning information systems (Riley and Smith 1997).

Our analysis is based on our participation in an incernational comparative study which we conducted recently (Steyaert et al. 1996). This was a country-bycouncry case-srudy analysis of a sample of countries from around the world, including from Europe: Belgium, Finland, Denmark, Germany, Greece, Ireland, the Necherlands, Romania, Russia, Spain, and the United Kingdom. For each country a case-study was prepared following a comparative framework which identified as the main dimensions of information technology implementation in the human services: the social policy context and organizational development of services; information for citizens; vocational education and training; and provision of services. This paper develops one dimension of this framework and unpacks the synergy berween policy, organization, and information technology. This reanalysis is supported by the authors' extensive research and consultancy experience in Europe. Taking Belgium, the Netherlands, and the United Kingdom as our primary examples we will reconsider some of the main foci of the social policy debate and their relation to information management: namely, the repositioning of social work; demand-driven care; the marketization of care; and the retrear of government. These four ingredients seem to dominate the current agenda of social policy as it relates to social services. The extent to which each dominates the social policy agenda differs from country to country, but they are common challenges. Neither does any of these developments stand on its own. There is a complex and dynamic interaction between them which reinforces their impact on social services.

\section{The repositioning of soclal work within social services}

The repositioning of social work has two aspects: a greater reliance on informal care and a general deprofessionalizacion of social work-greater subjection to managerialist direction, control of discretion through procedural diktat, and increased delegation of tasks to social care workers with lower levels of qualification, status, and income. $A$ benign interpretation of this process is that care can be given more appropriately and flexibly by those closest to the home or community environment. This sentiment can be identified in the UK context in the Barclay commitree's review of social work ('it is difficult to overestimate the importance of the social care that members of communities give each other' (Barclay 1982)) 
and is taken forward in the subsequent framing of community care policies. A more critical view has to be that this is part of a broader cost-curting agenda: faced by fiscal crises and escalating welfare costs, the burden of care had to be shifted by the state towards voluntary and informal (predominancly women's) provision ['the recommendations (of the Barclay report) were made in a political climate which had as its aim the reduction of state intervention into the lives of individuals' (Orme and Glastonbury 1993, p. 2)].

Although we have instanced the UK here, this is clearly an international trend. For instance, Flemish social policy was recently (1993) extended by an official regulation identifying the rights and duties of care volunteers. In the Netherlands, central government has created new funding and organizations to support families raking care of their dependent relatives. Similar organizations supporting or caring for volunteers and informal carers are mushrooming across Europe. This delegarion of care tasks to less qualified personnel, and the routinization of tasks previously involving professional judgement, also seems to be linked to the emergence of competencebased training to replace more critical and analytical professional education (Gould 1996).

The deprofessionalization of social welfare has several implications for information management. A substantial deprofessionalization of social welfare is likely to result in reduced availability and accessibility of social welfare information with detrimental effects for long-term planning and equitable resource allocation. Unpaid carers will nor, for understandable and practical reasons, give the same priority to structured and standardized information gathering as social services employees. Grandparents caking responsibility for the daycare of their grandchildren, adults nursing their own disabled child or a dependent parent are just a few examples of important (and often appropriate) non-professional care. However, each is also a situation in which information tools such as client files or statistical returns will be nonexistent. Hence, policy-makers will have to rely to a greater extent on compensatory surveys and research.

The centrality of information and information management to contemporary and future social work is something which is problematic for the prevailing professional culture. As Prince's research has shown, recording and information gathering is traditionally perceived as tedious, of little relevance to direct service delivery, and a distraction from expert practice (Prince 1996). Implementation of information technology has similarly encountered problems of professional resistance, is seen as the domain of technicists, a rool of behaviourism and managerial control, rather than a medium which reflects the values of the organizational context within which it is located (Phillips and Berman 1995). However, deprofessionalization of social care actually results in a need to be more pro-active in seeking and recording service information and referral information (who provides what care to whom, where, and when). The traditional scope of this information will have to be expanded beyond the formal organization-based care providers. Information on volunteers and self-help groups will have to be included. Intake workers will have to gather more substantial information about the social network in which the client or patient is embedded. Within a context of care provision through a mixed package of care the exchange of clinical and administrative data between professionals becomes increasingly important and sensitive. One care provider will only provide part of the care, and will have to be able to rely on and be informed about what others have already provided.

Aggregated social welfare information will have to reflect changing information needs. Statistical returns, in order to become or remain useful, will not only have to cover care provided by professional carers, but also that provided by others. Policymakers will have to face the fact that, even more than is already the case, the picture generated by statistics will cover only part of social welfare care. As we have mentioned, this repositioning of professional and informal care is an aspect of the shift from institutional to community care. This development will lead to an increased need for low- and hightechnology assistive technology that supports people's independent lives including alarm systems, 
mobility aids, and home adaptarions (Steyaert and Gould 1996).

\section{Demand-driven care}

An often-voiced critique of the organization of welfare service provision is that the fragmented structuring of agencies according to social problems (an agency for child abuse and neglect, anorher for childcare, another for family help, etc.) results in supply-driven care, by which we mean patterns of service decermined by agencies (suppliers) rather chan deriving from idenzified demands or needs of service users. For the service user this results in less Hexible and possibly less appropriate care, but the supposition has been that supply-driven or needs-led care will result in higher levels of care delivery than is strictly necessary or economically efficient. Whether this is a valid assumption is unclear, but it is safe to assume that the yearly level of a care agency's funding in a supply-driven care system is more subject to political and power interactions than to the estimared needs for their services. The sensitivity of and press incerest in its work area was and still is ofren more significane to a care agency's funding than the number of clients or referrals.

In order to reduce the shorrcomings of supplydriven care, social policy across Europe favours initiatives that strengthen demand-driven care. For example, this includes reduction of the fragmentation of service providers by stimulating cooperation, one-stop offeces that regulare the intake and management of care, and more rational resource allocation strategies reducing the level of possible discretionary power of civil servants or politicians.

Demand-driven care has, compared to supplydriven care, a number of implications for information management. At the policy level, it results in a need for information on social needs and its discribution across population and geographical areas. For some services, such as clinical social work or child abuse protection services, this is complex, as these needs are nor easily measurable. Under these circumstances, projected estimations of needs will be needed, based on theoretical or empirical relations berween needs and more easily measurable variables or historical data on previous care delivery. For example, when the Flemish child and abuse centres started receiving government funding for their work in the mid-1980s, the amoune was equal for all Flemish provinces. Later this allocation was refined, taking account of the population berween the ages of 0 and 18 in each of the provinces and their previous case-loads.

Such information on needs led to a revitalization of the social indicators movement and coding and classification systems in the social policy field (Sreyaert et al. 1995). It also resulted in a substantial amount of academic literature outlining the methadology and pitfalls of such an approach (Albert and King 1996; Berman 1992; Gould and Wright 1997). This development was taken forward due to the availability of accessible mapping software and the abundance of personal daca, made available through the automation of various administrative processes in human services (including government agencies). The porential for this approach is to shift service planning and commissioning rowards longrerm strategies to meet need, and away from shortterm expediency and crisis management of service development. The continuing imperative is to make sure that the voice of service users is heard through participation in the planning process, to ensure that it is not only normative professional definitions of need which are promored.

At the agency level, we see the development and implementation of front office-back office scenarios, with experimentation with intraner and knowledgebased systems. The one-stop front office (i.e. community-based reception areas providing single-point access to multi-agency services) potentially provides the client or patient with a coherent package of care, making the organizational structure of the back offices transparent for the end-user. As the frontoffice staff need broad generic skills, they are being equipped with powerful information and referral databases that may even include some artificial intelligence. It is unclear at the moment what the influence of these information technology applications may be on the pracrice of staff, particularly the discretion of 'street-level bureaucrats' (Lipsky 1990). It will be important to monitor that such systems 
enable service users to be genuine end-users and that they do not become the powerless objects of arcificial intelligence systems which merely reinforce traditional modes of professional power and discrerion.

For the service user a demand-driven social policy has different information management consequences. If the user can bring influence to bear as a consumer in the care process, it is to be expected that this person will shop for best value and buy services from different care providers (this is an ideological freemarker characterizarion of the service user as consumer-the reality for most marginalized and disadvantaged service users is that 'choice' is highly constrained). As such, there will no longer be a central organization that holds the individual client record. Consequently, the need arises to establish information management tools that allow sharing of information across organizational boundaries: examples would be smart cards holding patients' (administrative and/or clinical) data, or a crossroads database as is used in several social security systems. This raises particular requirements-returned to in the later discussion-for agencies and user-led organizacions to work towards shared definitions or a glossary of care terms to enable information transfer (van Yperen 1996) nor to mention more sophisticated regulation of access to and privacy of data (Glastonbury and LaMendola 1992).

\section{The marketization of care}

A significant element of the influence of neoliberalism on social policy has been the introduction of the market as a model for the organization of social services. Its attractiveness is that it supposedly results in the optimal efficiency-effectiveness ratio (Adam Smith's invisible hand) due to competition and active scrutinizing behaviour by purchasers. $A$ key aspect of the implementation of the market model in social services is the introduction of purchaser-provider relationships and the emergence of care management as a method for the commissioning and delivery of services. A definitional distincrion needs to be made berween the North American usage of the terms 'case management' (reflecting a tradi- tional professional social work concern with clinical casework) and 'managed care' (corporate-often insurance-based-delivery of care), and the European concept of 'care management'. Care management connotes the overall management of the care process including coordination of the care process, managemenr of care budgers, making purchasing arrangements, and allocating resources; all of which go some way beyond the conventional remit of social casework. As we have already indicated it makes assumptions abour consumption and choice within the quasi-market of social care which do not merit critical scrutiny (Sheppard 1995). Nevertheless, wichin the UK, the thrust of government guidance has been that local authorities should separate clearly the purchasing and provision of services. Other West European countries such as the Netherlands have pursued a similar policy.

There is neither a proven model, nor a statutorily prescribed model, for achieving such a separation. There could be within a social services organization a central strategic purchaser, or there might be an internal split at another level within the organization, or there could be an organizational separation with a strategic purchasing authority buying in services from external providers, including for-profit organizations. Some scenarios go furcher and devolve budgets to professionals (e.g. the GP fundholding experiment in the UK (Glennerster et al. 1994)) or to those in need (e.g. the person-based budgets for che disabled in the Netherlands). Free-market liberals suggest the introduction of vouchers, implicitly hoping for a substantial failure in take-up rates. All these scenarios have in common the aim of creating a market (an internal market, quasi-marker, or other variations of it) with vendors, although this has not been accompanied by a redistribution of purchasing power to support the participation of users as consumers.

In the UK the preference of the Conservative administration was clearly to reduce the role of local authorities to strategic purchasers with independent agencies providing services. Because of the autonomy accorded to local authorities there has been differentiation in the approaches taken, but the general evidence is that departments have progressively moved 
towards this deeper separation of functions berween a residual public purchasing aurhority and external providers.

In the Netherlands, there seems to be a preference for segmentation of the care process across different organizations and professions, with some acting as strong gatekeepers for the services of the others, for example the whole youch care service has been reorganized and will subsequencly be influenced strongly by the regional 'yourh care bureaux'. These take care of the intake, assessment, and care-matching segments of the care process and act as powerful gatekeepers to orher residential or non-residential youth care. Similarly, local authoricies were recencly entrusted with the gatekeeper's function in terms of home care and long-term residential health care. Powerful groups are currently calling for the general practitioner to become a gatekeeper for mental health care.

The capacity to operate a care-management system, whatever its specific configuration, requires information and information management systems that were neither needed nor available within tradicional public-sector organizations. Traditionally, in social services no one knew how much any form of intervention cost or how much of it was being provided. Care management requires knowledge of unit costs, and full service costs. As Orme and Glastonbury identified, care management requires an information system which provides: financial information to devolved budgets and costs for individual packages of care; a resources database giving up-to-dace information on providers of services; assessment of individuals' needs; decails of individual care packages; budger details for individuals, with a record of current expenditure; and availability of specific services (Orme and Glastonbury 1993).

The research suggests a mixrure of positive and negative effects of information rechnology usage in this area. Although budget transfers create large invoicing tasks which have made great demands upon IT-based fnancial systems, the implementation of such systems, 'provides more coherent thinking abour purchasing for particular client groups and also enables service purchasers to effect service alcerarions by requiring alterations in one area in order to secure expansions in another' (Lewis and Glennerster 1996, p. 83). In the Uniced Kingdom different auchoricies were at differenc stages in the development of information systems at the point of the incroduction of community care in the early 1990s, and consequently there has been a great deal of differentiation in responses to the management of the information demands of care management. Some have opred for comprehensive solutions replacing all previously existing piecemeal systems, while others have opred for incremental adaptation and innovation. In both scenarios there are what Lewis and Glennerster have called 'second wave' changes as new systems are iteratively refined to make them more relevant and user-orienced (Lewis and Glennerster 1996, p. 95). Whatever the specifics of an agency's system, the universal experience is that the provision of services is a process that is increasingly informacion-driven.

The deregulated welfare state, with budgets devolved to the level of citizens, assumes that individuals will be able to make informed choices about the range of alternatives open to them. However, research into communicy care shows that the exercise of choice in this sphere is characterized by very high levels of uncertainty (Baldock and Ungerson 1994) and porential reinforcement of pacterns of social exclusion (Moore 1997). People are unclear abour who is responsible for the provision of particular services, for instance where responsibility lies for providing long-term nursing care between social services, health authorities, family doctors, etc., what the criteria of encitement mighe be, or what the oprions are for the delivery of care. The normative theory of a free marker in welfare assumes a situation of perfect choice underpinned by a free availability of information about the full range of options. The reality is highly differentiated levels of access to information between the information-rich and information-poor, which is highly correlated with other bases of social exclusion, such as class and echnicity (Sreyaert and Gould 1997). Applications such as welfare-benefic calculations systems might address this differential non-take-up of enticlements.

Similarly an unintended consequence of the creation of social care markets is that it porentially 
creates a commercial value for the information contained in client files for agencies. Apart from their conventional clinical and administrative value, client data become an important business resource that allow the agency to develop users' profiles which could be distributed and markered (for instance domiciliary care information about future demand for residential care); again the technology creates an area of activity requiring regulation.

Care management that includes the segmentation of care across different organizations creates important gatekeepers who monitor and control the 'point of entry' into funded service provision. Technology can interact with organizational structure to reinforce the power of such individuals (Scarborough and Corbetr 1992). Providers and policy-makers consequently have a great incerest in scrutinizing the professional knowledge and decision-making processes of these gatekeepers. For example, in the experiment with GP fundholding carried out in the UK, this resulted in fake patients visiting GPs to check on their inregrity and professional comperence (Sunday Times, 18 August 1996). Consequently, substantial research and development work is carried out to formalize and validate new and exiscing methods of assessment and care matching. Although early efforts have resulted in the development of automated assessment tools (Bloom 1992; Nurius 1990), there is little evidence of widespread implementation of these instruments in agencies. However, protocols for care provision are being developed in several human services, such as psychiatry and health care. Within social services, this development is limited to experiments and initial rests. Protocols formalize and validate the actual service provision and may lead the way to renewed interest in clinical expertise software, norwithstanding the poor results of expert system development in the 1980 s.

\section{Retreating government}

As ouclined in the introduction to this paper, governments have repositioned themselves in respect to their responsibilities for the welfare of citizens. Governments have retreated from the welfare state by limiting budgets for welfare, by leaving social service provision to others (funded, commercial, or voluntary carers) and by retreating from the social policy arena. As governments move away from universalistic social policies and the provision of safery-nets for citizens who meet adversity, so the responsibility for making provision against misfortune is shifted to the individual. At the normative or ideological level this has been justified by governments in terms of the comperitiveness argument (Gough 1996), i.e. that the burden of welfare spending handicaps economic flexibility, but also by making a moral case that consumers of welfare should be free to exercise choice racher than receive monopolistic services from the 'nanny state'. As Klein and Millar have argued, this constitutes one of the major normative trends in social policy during recent decades, the shift from rop-down provision towards individuals constructing their own mix of services from the public and private seccors (Klein and Millar 1995). Generally, this has resulced in a lowering of the coherent, state-provided 'safery-net' and a myriad of self-service social policy options which citizens can select and pay for (although for the many withour purchasing power the choices remain scarce or non-existent).

Although there is an orthodoxy which states that this is an effect of neo-liberal political dominance in the $1980 \mathrm{~s}$, that the liberty of the individual to choose is paramount, it is clear that the left had also moved away from collectivist solurions towards a view of empowerment as a guiding principle of welfare which included the right to choose. What has emerged is a synthesis berween a modified welfare state incorporating internal or quasi-markets, and an expanded independent (incorporating private and charitable) sector. This is a picture which applies broadly across a range of public services, but particularly in the health and social services felds. For some countries, it implies a major shift from the past, for others it is a redefinition of an already existing welfare infrastructure based on subsidiarity.

Although social policy analysts have begun to respond to this new paradigm, in particular the need to refocus from a concentration on the behaviour of elites in the policy process rowards the decisionmaking behaviour of 'consumers', there has been 
litcle attention as yer given to the informational implications of this shift. And yet there are at least three levels at which information management in social services will change as a consequence of retreating governments.

The first implication involves the information flows berween care providers and government. As government (at all levels) retreats by making less provision, there is a growing need for structured information exchange between private care providers and government, e.g. previously the Dutch ministry of welfare had no need for proper reporting on employment in social welfare, because its position as employer generated any necessary person-power data. Now, chese budgets are devolved to the level of local authorities and the central ministry is left with a new and growing information need that results in an increased How of staristical information from service providers to government. The need for information through social service statistics will expand proportionately with the distance between government and the care provider.

A second informational implication of retreating government is the issue of regulation. Not only does the state retreat by limiting the welfare budget and being less involved with care provision, it also becomes a different actor in the social policy arena. Here, however, we see concradictory tendencies. In the UK, as the state comes to provide fewer and fewer services, it becomes more involved at the regulacory level. It is well documented that the reduction in numbers of civil servants and direct employees of local government has been accompanied by an exponential growth of public employees working as part of inspectorial and regulatory agencies (Day al. 1996). In orher countries (such as the Nerherlands or Flanders), the contrary happens. The state not only devolves budgets to lower government levels, but also becomes less regulatory by leaving more to the autonomy and self-regulatory capacity of the agency or professions. Both councries mentioned have in recent years adopted stacures on the quality of social services in which no quality parameters are described except for the obligation for each agency to have a quality policy and quality improvement tools.

Thirdly, the increasing differentiation and frag- mentation of care-giving creates highly complex issues for the commissioning and strategic planning of services. Although marker principles have been introduced into human service provision, as Le Grand and others have argued these have been quasimarkets within which central and local government retains a purchasing and commissioning function. The free operation of the market is constrained by a residual state responsibility rowards ensuring a distriburion of services that is assessed to relate to need or demand. Traditionally, planning for services has been based upon normative methodologies, that is a calculation of necessary service levels expressed as a proportion of the toral population (c.g. number of residential care beds per thousand people). This is generally calculaced using epidemiological evidence combined with information about patterns of demand (Gould and Wright 1997). As users of services follow increasingly individualistic parhways through the care system, based on their particular do-it-yourself welfare mix, so a popularion focus for planning becomes increasingly difficult to achieve (Pollock and Godden 1997). Those using publicsector services are likely to become arypical of the rotal population of services users; adverse selection operates by which there is a concentration within those services on people with complex and expensive needs, whilst those who can afford private care and particularly those with less complex needs are more likely to make use of the independent sector. Presuming that commissioning auchorities will have fewer data relating to users of independent service providers, it becomes increasingly diffcult to generalize from data about known public-sector users and more difficult to interpret variations in demand for services. Increasingly, social service agencies are having to develop methodologies and information systems which can accommodate and compensate for these shifts in the social policy environment.

\section{Conclusion}

This paper started by outlining the major challenges the social services face across Europe and their core social policy responses. We then described in more 
detail each of the ingredients and the consequences they have or can have for information management in social services. The argument can be read at different levels. On a pragmatic, descriptive level, this paper provides an overview of the major current social policy developments in Western European social services, as well as the major information management issues being faced. As such, it offers an elaboration of one aspect of the framework we used in our international comparative studies of information management in social services (Colombi et al. 1993; Qvortrup et al. 1992; Steyaert et al. 1996).

On a more generic level, we attempted to group social policy developments and information management developments together by suggesting a relationship between them. We already hinted that this is a complex and interactive relationship, certainly not uni-directional. As such, this overview allows for reflection about the relationship between social services and information management and some grounded crystal-ball gazing about fucure scenarios, some of which are described in the following paragraphs.

First, there is the need for more accessible, accurare, and reliable data on popularions, needs, and care provision at national, regional, and local levels. This has a number of implications:

- Increased effort to gather, process, and use comparative social welfare statistics (Steyaert et al. 1995) based on clear definitions of personal social services.

- Increased need for a common language across agencies and professions through coding and classification agreements.

- More structured formars of client records and files.

- Establishment of dedicated offices in the area of social welfare, which can act as data warehouses and information incermediaries

As we have argued, whether described as postFordist or globalized, the fragmentation of services threatens the loss of a population focus to planning and commissioning of services at the local level. Given that there is a general convergence towards mixed economies of care across Europe, there is a shared research agenda to develop methods of need assessment which can reconcile top-down service-led measurements of need, with bottom-up populationbased surveys of need.

The organizational rearrangements caused by marketization and segmentation of social care already result in increased interest in the knowledge base of each care segment, especially the assessment procedures, evaluation of outcomes, and treatment protocols. It also brings into the social service arena a problem health care has already been addressing for several years: how to structure client data and information flows in such a way that they can cross organizational boundaries. The technology suppliers are eager and ready to introduce smart cards, bur it is evident that this problem requires approaches that go far beyond pure technology.

There is a need for clear articulation of the necessity for information management to be located in a value-based professional culture which actively promoces social inclusion, social cohesion, equal access to information, and broader participation in the development and implementation of information systems.

On a more theorerical level, our overview serves as a case that enables critical reflections on current debates about the impact of new technology and globalization (Kumar 1995). Several authors have usefully brought atcention to patrerns of convergence between organization and forms of practice in European social services. However, there is a danger that the globalization thesis can become a form of reductionism which obscures complexity in the process of change, and overstates the negative impacts of variables such as new technology. Rather than see 'technologization' as having a one-way effect on producing forms of social service intervention which are dehumanizing and deprofessionalizing, there is a need to appreciate the dialectical relarionship between policy, organizational structure, and rechnology.

As we have argued, European social services are being shaped by national policies which reflect a concern with the impact of the global economy, in parricular that efficiency should be raised by exposure to market forces so as to maximize competitiveness and flexibility. This is producing marketization of 
sacial services as well as the implementation of new forms of professional intervention such as care management. These changes have the paradoxical effect both of requiring sophisticated information systems, supported by compurer rechnology, to implement and manage the delivery of care, but at the same time the quality of information collected by agencies potentially becomes fragmented, incomplete, and less reliable. Technology thus becomes a key resource, and information management a critical arena, for the development of forms of care which are both responsive to need at the local level, but also shaped by information-based strategic planning and commissioning.

As social services become less 'Fordist' in their structure-that is hierarchical and monopolisticbut instead arranged around core and periphery networks (James 1994), so the role of information management as an independent variable becomes more apparent. The capability of smaller, more specialist agencies to coordinate activities, and the ability of service users to access the facilities they need is likely to be closely relaced to the implementation of the kinds of integrated, Hexible, networked, and userfriendly information systems which are made possible by the availability of the internet, intranets, and groupware. Information management and its technologies need to be analysed for their porentialities racher than simply assumed to be the servant of bureaucratic management.

\section{Acknowledgements}

The authors are grateful for the helpful comments of swo anonymous reviewers.

\section{References}

Albert, V. and King, W. (1996) Allocaring resources for child welfare services: rhe effect of a caselcad-driven approach, Adninistration in Sacial Work, 20, pp. 61-77.

Baldock, J. and Ungerson, C. (1994) Becouning Consumers of Consmunity Care, York, Joseph Rowntree Foundarion.

Barclay, P. (1982) Sacial Worken: Tbeir Rale and Task, London, Nacional Instituce for Social Work.

Berman, Y. (1992) A decision support system in resource allocation: the political process in mational decision making. New Technology in the Humon Services, 6, pp. 8-19.
Bloom, B.L. (1992) Computer-2ssisted psychological intervention: a review and commentary, Clinical Prycbalogy Review, 12, pp. $169-197$.

Brewer, C. and Lait, J. (1980) Can Sacial Work Survive? London, Temple Smith.

Burrows, R. and Loader, B. (eds) (1994) Towards A Pass-Fordist Wuffore Stase? London, Roudedge.

Colombi, D., Rafferty, J., and Steyacrt, J. (1993) Humban Services and Information Tabrology: A Exropean Perspative, Antwerp, European Network for Informarion Technology.

Day, P., Klein, R., and Redmayne, S. (1996) Wby Regulate? Regulating Residential Can for Elderly People, Bristol, The Policy Press.

Dominelli, L. and Hoogvelt, A. (1996) Globalization and the technocracization of social work. Critical Sacial Policy, 16, pp. $45-62$.

Esping-Andersen, G. (1990) Tbe Tbree Worlds of Welfare Capitalism, Cambridge, Policy Press.

Evers, A. and Sverlik, I. (eds) (1991) New' Welfare Mixes in Care for she Elderly, 1. Intradution: Cerborlovatia, Hungary, Poland, Yugarlavia, Vienna, European Cencre for Social Welfare Policy.

Ferge, Z. (1997) A central European perspective on the social quality of Europe, in Beck, W., van der Maesen, L., and Walker, A. (eds) The Social Qualing of Exrope, The Hague, Kluwer, pp. 165-181.

Fischer, J. (1978) Does anyrhing work? Jourmal of Saial Servive Researib, 1, pp. 215-243.

Glastonbury, W. and LaMendola, W. (1992) Tbe Integrity of Intelligence: A Bill of Rigbss for tbe Information Age, Basingstoke, Macmillan.

Glennerster, H. and Midgley, J. (eds) (1992) Tbe Radical Rigbt and tbe Welfare State: An Intemational Assessment. London, Harvester Whearsheaf.

Glennerster, H., Matsaganis, M., Owens, P. and Hancock, S. (1994) Implewenting GP Fundbalding: Wild Card or Winning Hand? Buckingham, Open Universiry Press.

Gough, I. (1996) Social welfare and competitiveness, in Millar, J. and Bradshaw. J. (eds) Social Welfare Sysrews: Tourards A Reseanth Agenda, Bath, Universicy of Bath/Economic and Social Research Council.

Gould, N. (1996) Social work, information technology and the post-Fordisc welfare stace, in Glastonbury, B. (ed.) Dreamss and Realities: Information Technology in the Humban Services, Helsinki, STAKES, Pp. 2l-34.

Gould, N. and Wright, J. (1997) Adding up the sums: populacion-besed planning for unitary local auchoroties, in Gould, N. and Moultrie, K. (eds) Effative Policy, Planning and lupplemeneation: Information Managentent in Sacial Services, Aldershot, Avebury, pp. 48-65.

Hood, C. (1991) A public managemenc for all seasons, Public Adncinistration, 69, pp. 3-19.

James, A. (1994) Managing to Care: Public Service and the Market, London, Longman.

Klein, R. and Millar, J. (1995) Do-it-yourself social policy: 
searching for a new paradigm, Sacial Policy and Adninistration, 29, pp. 303-316.

Kumar, K. (1995) Frowt Past-Industrial so Post-Modern Sociery: New Theories of tbe Conemporary World, Oxford, Blackwell.

Lewis, J. and Glennerster, H. (1996) Implententing tbe New' Contmunity Care, Buckingham, Open University Press.

Lipsky, M. (1990) Street Level Bureaukracy, New York, Russel Sage Foundation.

Lovell, R. (1994) (ed.) Managing Cbange in tbe New Public Settor, Harlow, Longman.

MacDonald, G. and Sheldon, B. (1992) Concempomry studies of the effectiveness of social work, Britisb Jaumal of Social Work, 22, Pp. 615-643.

Marx, K. and Engels, F. (1848) The Conmsenist Manifesto, London, Lawrence and Wisharr.

Moore, C. (1997) Social exclusion, technology and the learning sociecy, Saxial Develofment Revieu (Supplanent on Produttive Employmuent), 1:3, pp. 3-4.

Munday, B. and Ely, P. (eds) (1996) Sacial Care in Europe, London, Prencice Hall.

Nurius, P. (1990) A review of automated assessment, Computers in Hemuan Services, 6, pp. 265-281.

Orme, J. and Glastonbury, B. (1993) Care Managenvent, Tasks and Workloads, London, Macmillan.

Phillips, D. and Berman, Y. (1995) Humlen Services in the Age of New' Tecbnology: Honnonising Sacial Work and Computerisation, Aldershot, Avebury.

Pollock, A. and Godden, S. (1997) Can we open the black box of care assessment? in Gould, N. and Moultrie, K. (eds) Effecrize Policy, Planning and Inplementusion: Infornution Management in Saciul Services, Aldershor, Avebury, pp. 74-90.

Prince, K. (1996) Boring Records: Communication, Spectb and Writing in Saial Work. London, Jessica Kingsley.
Qvortrup, L., Glastonbury, B. and De Graaf, H. (1992) European Resounce Book: Information Tecbrology and Humlan Services, Utrecht, NIZW.

Riley, L. and Smith, G. (1997) Developing and implementing IS: a case study analysis in social services, Journal of Informastion Tacbnalogy, 12:4, pp. 305-322.

Scarborough, $H$. and Corbett, J (1992) Tecbnology and Organisation: Power, Meaning and Design, London, Rourledge.

Sheppard, M. (1995) Care Management and the New Saidal Work: A Critical Analysis, London, Whiting and Birch.

Steyaert, J., Benbenishty, R., and Silon, L (1995) Developing comparative social welfare statistics, EuraSatial Report, Vienna, European Centre for Social Welfare.

Steyaert, J., Colombi, D. and Rafferty, J. (eds) (1996) Human Services and Information Technology: An International Perspective, Adershot, Arena.

Steyaert, J. and Gould, N. (1997) Sacial Aspects of the Information Saciery: Transmogrifying lsswes and Appracibes to Sacial Policy, Rijswijk, Ministry of Health, Welfare and Sports.

Trevillion, S. (1996) The globalisation of European social work, Social Work in Europe, 4, pp. 1-9.

van Yperen, T. (1996) On coding and classification in social welfare, Neu' Tethnology in Humun Services, 9:3, pp. 3-11.

\section{Authors' addresses}

Dr Jan Steyaert, Fontys University of Higher Professional Education, Postbus 347, NL.5600 AH Eindhoven, The Netherlands

E-mail: J.Steyaert@fontys.nl

Dr Nick Gould, Department of Social and Policy Sciences, University of Bath, Bath BA2 7AY UK E-mail: hssng@bath.ac.uk 